\title{
Isolation and propagation of endothelial cells derived from rheumatoid synovial microvasculature
}

\author{
C J JACKSON, ${ }^{1}$ P K GARBETT, ${ }^{1} \mathrm{R}$ M MARKS ${ }^{3}$ G CHAPMAN,${ }^{4}$ \\ D H SONNABEND, ${ }^{2} \mathrm{~S}$ R POTTER, ${ }^{2}$ P BROOKS, ${ }^{1}$ AND L SCHRIEBER
}

From the Sydney University Department of ${ }^{1}$ Rheumatology and ${ }^{2}$ Orthopaedics and Traumatic Surgery, Royal North Shore Hospital, St Leonards, NSW, Australia; the ${ }^{3}$ Department of Pathology, University of Michigan Medical School, Ann Arbor, Michigan, USA; and the ${ }^{4}$ Centre for Immunology, St Vincent's Hospital, Sydney, NSW, Australia

SUMMARY Synovial angiogenesis may play an important part in the destruction of articular cartilage in patients with rheumatoid arthritis (RA). As an important first step towards developing in vitro models of synovial angiogenesis, microvascular endothelial cells have been isolated, purified, and cultured from operative synovial specimens obtained from adult patients with RA.

Rheumatoid arthritis (RA) is the most common chronic inflammatory rheumatic disorder of mankind and represents a major cause of morbidity in the community. ${ }^{1} \mathrm{~A}$ characteristic of the disease is the outgrowth from the synovium of pannus, a fibrovascular granulation tissue. This progressively invades the articular cartilage, ${ }^{2}$ a structure normally resistant to vascularisation, ${ }^{3}$ resulting in irreversible destruction of cartilage and bone. The growth of new blood vessels (angiogenesis) is an essential component of pannus formation and is thought to contribute to joint destruction. ${ }^{4}$

Angiogenesis is important in a number of physiological and pathological processes, including embryogenesis, the growth of solid tumours, and wound healing, as well as in the development of rheumatoid pannus. ${ }^{5}$ The angiogenic potential of both rheumatoid synovial fluid $^{6}$ and synovial macrophages ${ }^{7}$ has been shown with in vivo models of angiogenesis in experimental animals.

Advances in understanding angiogenesis have come from the development of in vitro models using cultured human microvascular endothelium. ${ }^{8}$ Such techniques have now been adapted to study the growth of human dermal microvascular endothelium, both in monolayers and in three dimensional gels of fibrin or collagen. ${ }^{9-11}$ It has been recently reported, however, that microvascular endothelium

Accepted for publication 23 January 1989.

Correspondence to Dr C J Jackson. Sydney University Department of Rheumatology, Royal North Shore Hospital, St Leonards, NSW 2065. Australia. derived from different tissue sources displays distinctive tissue specific characteristics. ${ }^{12} 13$ Thus to understand the development of rheumatoid vascular disease and angiogenesis an important first step is the isolation and culture of microvascular endothelium from the rheumatoid synovium.

\section{Materials and methods}

ISOLATION OF SYNOVIAL ENDOTHELIUM Operative synovial specimens were obtained from the knee joint or the olecranon bursa of adult patients with RA and immediately placed in cold calcium/magnesium free Hanks's buffered salt solution (HBSS; Commonwealth Serum Laboratories, Sydney, Australia). Endothelial cells were isolated by a modification of the method of Marks et al. ${ }^{14}$ Tissue was cut into $5 \mathrm{~mm}$ cubes and incubated with continual shaking in $0.6 \%$ trypsin 1:250 (ICN Biomedicals, Cleveland, Ohio, USA) and $0.4 \%$ pronase (Calbiochem, San Diego, California, USA) in HBSS for 5-10 minutes at $37^{\circ} \mathrm{C}$. Fragments were washed five times with HBSS and capillary segments were squeezed from the cut edges by downward pressure with the flat side of a scalpel blade. The segments were resuspended in $400 \mu$ l minimum essential medium D-valine modification (Sigma, St Louis, USA) containing $40 \%$ normal pooled human serum, $100 \mu \mathrm{g} / \mathrm{ml}$ endothelial cell growth supplement (Collaborative Research, Bedford, Massachusetts, USA), $100 \mu \mathrm{g} / \mathrm{ml}$ heparin (Sigma H9133), $2.5 \mu \mathrm{g} / \mathrm{ml}$ Fungizone, and the antibiotics 
penicillin $(100 \mathrm{U} / \mathrm{ml})$ and streptomycin $(100 \mu \mathrm{g} / \mathrm{ml})$. Minimum essential medium D-valine modification was used to inhibit fibroblast proliferation, ${ }^{15}$ though in our hands only minimal inhibition was found.

A $100 \mu \mathrm{l}$ droplet of cell suspension was placed in the centre of each of four gelatin coated $35 \mathrm{~mm}$ tissue culture dishes (Lux, Flow Laboratories) and cells allowed to adhere overnight in a humidified incubator at $37^{\circ} \mathrm{C}$ in a $95 \% / 5 \%$ air $/ \mathrm{CO}_{2}$ atmosphere. The dishes were then washed twice in HBSS, fresh medium added, and the preparations inspected for contaminating cells by inverted phase contrast microscopy.

PURIFICATION OF SYNOVIAL

EN DOT H E L I U M

Endothelial cells were initially identified morphologically. The contaminating cells, predominantly spindle shaped fibroblastoid cells, were eliminated by two methods. Firstly, 24 hours after isolation they were physically destroyed by surgical diathermy under $\times 100$ phase microscopy as previously described. ${ }^{16}$ Four days after isolation the cells were pooled and grown to confluence in a $35 \mathrm{~mm}$ dish. Secondly, further purification of synovial endothelial cells was achieved by sorting with a Coulter EPICS V flow cytometer (Hialeagh, Florida, USA) after exposure to $1,1^{\prime}$-dioctadecyl-1-(3,3,3',3'tetramethyl)indocarbocyanine perchlorate labelled acetylated low density lipoprotein (DiI-Ac-LDL; Biomedical Technologies Inc, Stoughton, Massachusetts, USA), which is selectively ingested by endothelial cells as described by Voyta et al. ${ }^{17}$ Briefly, between days 5 and 12 after isolation confluent cells in a $35 \mathrm{~mm}$ culture dish were incubated with $10 \mu \mathrm{g}$ DiI-Ac-LDL for four hours,

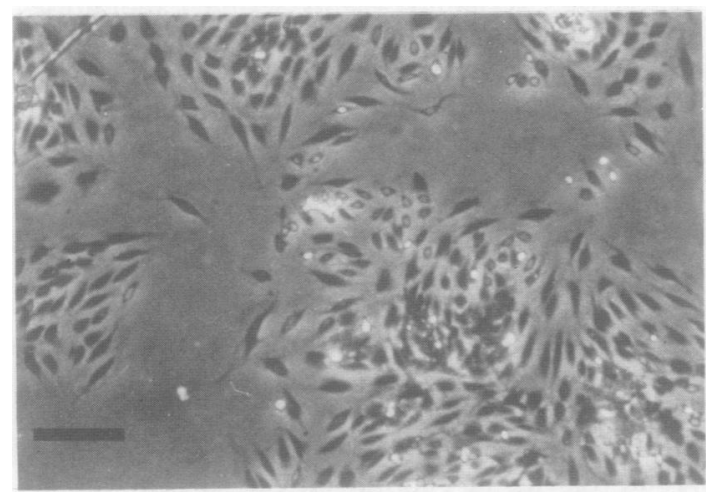

Fig. 1 Primary culture showing discrete colonies of synovial endothelial cells 24 hours after the initial isolation from rheumatoid synovium. Bar $=75 \mu \mathrm{m}$.

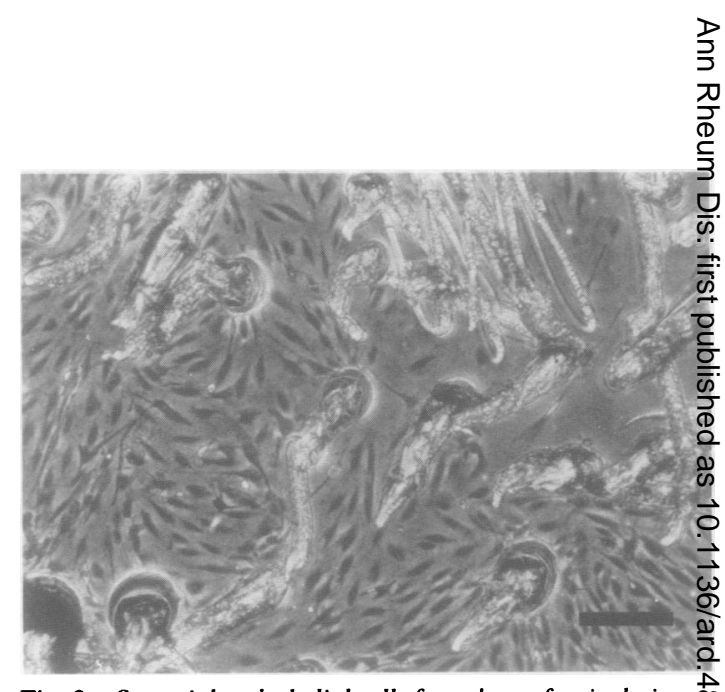

Fig. 2 Synovial endothelial cells four days after isolation. $\stackrel{\oplus}{\infty}$ These cells were weeded on days 1 and 2 to prevent overgrowth by fibroblast-like cells. The scratch marks in theे plastic dish show where weeding was performed. Bar $=100 \mu \mathrm{m}$.

detached with $0.05 \%$ trypsin (Difco, Detroi Michigan, USA) $/ 0 \cdot 02 \%$ diaminoethanetetra-acet acid (Sigma), washed and resuspended in HBSS and sorted by flow cytometry. The high fluoresce $\vec{B}$ (endothelial cells) and low fluorescence (containto nating cells) populations were collected separasely and grown to confluence. The endothelium identified by its expression of von Willebrand factor antigen using immunofluorescence. ${ }^{14}$ The purifie endothelium was maintained in $\mathrm{BM} / 86-$ Wissle्êt medium (Boehringer Mannheim, GmbH, West Germany) containing $20 \%$ human serum, $100 \mu \mathrm{g} / \mathrm{m}$ endothelial cell growth supplement, and $100 \mu \mathrm{g} / \mathrm{m}$ heparin.

\section{Results}

Primary cultures observed 24 hours after isolation had formed discrete rounded colonies with typical endothelial morphology (Fig. 1). In more than $80 \%$ of isolations attempted endothelial cells were prêsent. The number of endothelial colonies from different synovial specimens varied between 10 a 100 , with small colonies consisting of as few as tw to three cells and some larger colonies havios hundreds of cells. Contaminating cells represent up to $50 \%$ of total cell numbers on the first da\$ Predominantly these had fibroblast-like morphology and if untreated quickly overgrew the endothelium.

To eliminate non-endothelial cells two techniquess were used. Firstly, weeding was used to contro fibroblast growth until endothelial cells becane confluent (Fig. 2). On some occasions weeding wa्वे sufficient to eliminate all contaminating cells, thifs 


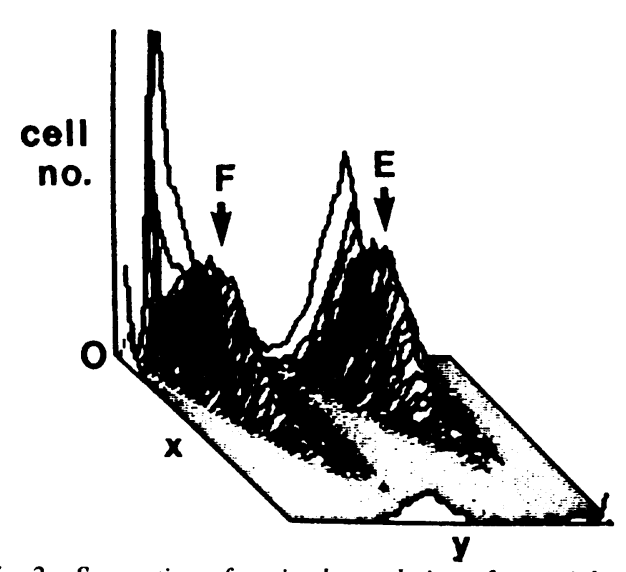

Fig. 3 Separation of a mixed population of synovial cells by flow cytometry based on 1,1'-dioctadecyl-1$\left(3,3,3^{\prime}, 3^{\prime}\right.$-tetramethyl) indocarbocyanine perchlorate labelled acetylated low density lipoprotein uptake. Discrete populations of low fluorescent cells $(F)$ and highly fluorescent cells $(E)$ were obtained. $x$ Axis =forward angle light scatter (cell size); $y$ Axis =log integrated green fluorescence.

providing a pure endothelial cell line. In more than $90 \%$ of cases, however, a second method of purification, using flow cytometry to sort the cells based on their ability to take up DiI-Ac-LDL, was required. At this stage cells were discarded if more than $50 \%$ contamination was evident ${ }^{\circ}$ by visual inspection. Two distinct populations of cells were found and subsequently separated by flow cytometry (Fig. 3). Cells with strong uptake of DiI-Ac-LDL grew with typical endothelial morphology (Fig. 4b), whereas the cells with low uptake of DiI-Ac-LDL had fibroblast-like morphology. In less than $20 \%$ of the attempted cell separations by flow cytometry slight fibroblast contamination of purified endothelium was evident. In such cases no further purification was attempted and all cells were discarded.

Synovial endothelium displayed morphology typical of microvascular endothelium and grew to confluence as a cobblestone-like monolayer. Synovial endothelium also showed a positive perinuclear fluorescence pattern for von Willebrand factor antigen (Fig. 5), whereas the fibroblast-like cells were uniformly negative. These purified endothelial cells showed no evidence of fibroblast contamination on subsequent passage.

\section{Discussion}

The potential importance of synovial angiogenesis in the pathogenesis of cartilage destruction in RA has only recently been appreciated. Normal articular cartilage is avascular and resistant to invasion by both tumours and by new vessel growth. ${ }^{3}$ In RA this

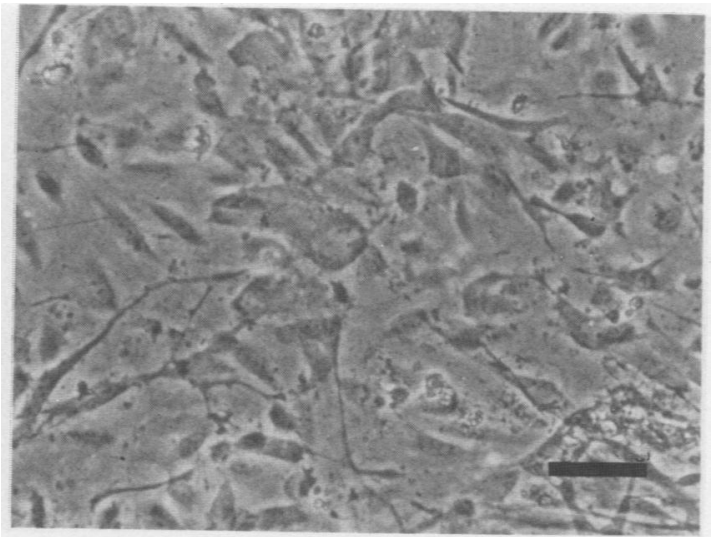

Fig. $4 \mathrm{a}$

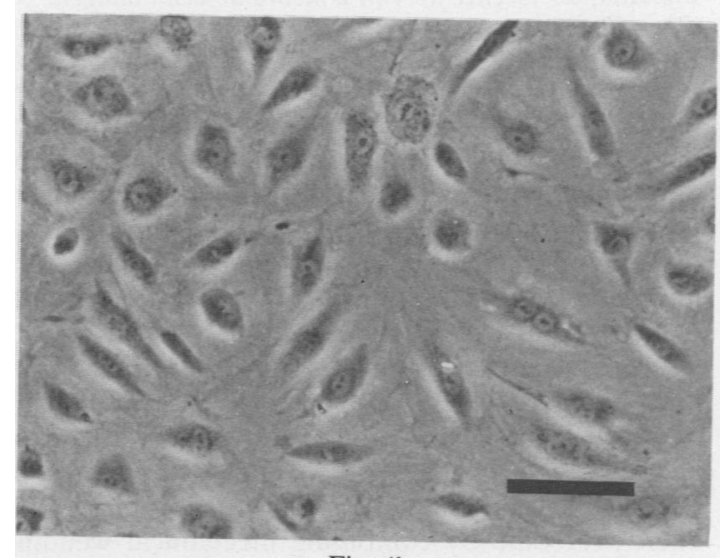

Fig. $4 \mathrm{~b}$

Fig. 4 (a) Overgrowth of synovial endothelial cells by spindle shaped fibroblasts. After sorting by flow cytometry the population with (b) high uptake of 1,1'-dioctadecyl-1$\left(3,3,3^{\prime}, 3^{\prime}\right.$-tetramethyl)indocarbocyanine perchlorate labelled acetylated low density lipoprotein grew with typical endothelial morphology. Bar $=50 \mu \mathrm{m}$.

barrier is broken and blood vessels grow into the articular cartilage and contribute to its destruction. Whether this results from an excess of proangiogenic factors or a loss of the normal cartilage inhibitors of angiogenesis is unclear.

Two models, the rabbit cornea and the chick allantoic membrane, have been used extensively to study angiogenesis. These in vivo techniques have many limitations. Firstly, the angiogenic response observed with such models may be due to a non-specific inflammatory reaction rather than to the angiogenic capacity of the agent being studied. Secondly, these methods are hard to quantify. Thirdly, such in vivo techniques cannot ethically be 


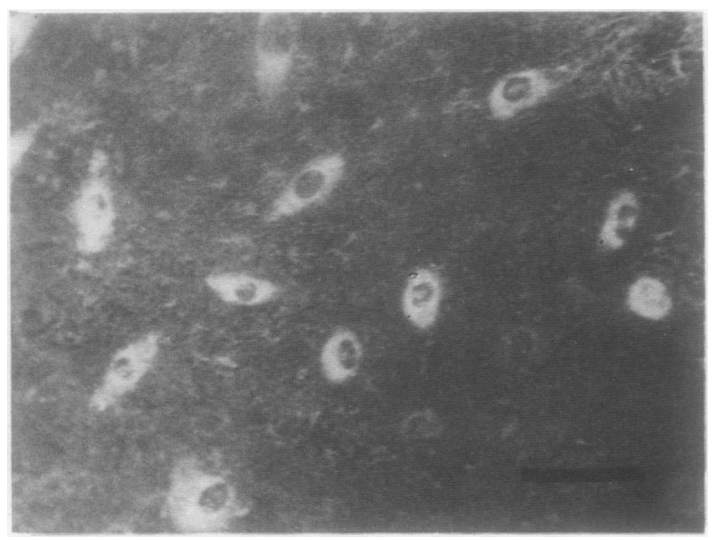

Fig. 5 Synovial endothelium shows positive immunofluorescence for von Willebrand factor antigen. Bar $=50 \mu \mathrm{m}$.

used to study synovial angiogenesis in man. Endothelial cells from different tissue sources show different phenotypic characteristics. ${ }^{12} 13$ Therefore to study synovial angiogenesis it is important to obtain endothelial cells from synovium. Here, we have isolated and cultured rheumatoid synovial microvascular endothelium.

Synovial endothelium has been identified by its morphology, uptake of acetylated low density lipoprotein, and expression of von Willebrand factor antigen. The problem of overgrowth with nonendothelial contaminants such as fibroblasts has been overcome by combining mechanical weeding and flow cytometry. Physical destruction alone often provided incomplete eradication, requiring tedious repetition. The preferential uptake of Dil-Ac-LDL by the rheumatoid synovial endothelium is consistent with the behaviour of other endothelial populations. $^{17}$

Primary cultures derived from different tissue specimens showed wide variability in the number and size of the endothelial colonies. This was independent of variations in technique or enzyme batches and may reflect differences in the degree of neovascularisation and the calibre and number of different vessel types present.

This preliminary study did not compare the behaviour in culture or electron microscopic morphology of endothelial cells from rheumatoid synovium with osteoarthritic or normal synovium or synovium from other vascular beds. These studies are in progress and will be the subject of a future communication. Nevertheless, the isolation of synovial microvascular endothelium should enable the study in vitro of the factors that regulate rheumatoid synovial angiogenesis. Furthermore, it offers the potential to assess a novel approach to the treatment of RA-namely, the use of antiangiogenic agents - . that may enable the prevention of the destructive phase of RA.

The authors wish to thank Christine Hicks for expert technicaf help, the orthopaedic surgeons at Royal North Shore Hospital for their kind cooperation in providing synovial specimens, and Mrs Shirley Humphrey for typing the manuscript. The project wa $\$$ supported by grants from the Arthritis Foundation of Australia, the Australian Mutual Provident Society of Australia, and the Suttofe Rheumatism Research Fund. Chris Jackson is the recipient of the Benjamin award from the Arthritis Foundation of Australia and the Wenkart Foundation scholarship.

\section{References}

1 Scott D L, Coulton B L, Symmons D P M, Popert A J. Lon term outcome of treating rheumatoid arthritis: results after 200 years. Lancet 1987; i: 1108-10.

2 Harris E D Jr. Pathogenesis of rheumatoid arthritis. In: Kelly W N, Harris E D Jr, Ruddy S, Sledge C B, eds. Textbook of rheumatology. 2nd ed. Philadelphia: Saunders, 1985: 886-915

3 Eisenstein R, Sorgente N, Soble L W, Miller M, Kuellner K E The resistance of certain tissues to invasion: penetrability of explanted tissues by vascularised mesenchyme. Am J Pathøb 1973; 73: 765-72.

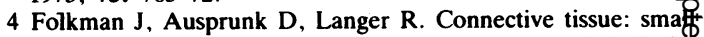
blood vessels and capillaries. In: Kelly W N, Harris E D J Ruddy S, Sledge C B, eds. Textbook of rheumatology. 2nd e⿻্ఠ Philadelphia: Saunders, 1985: 197-211.

5 Folkman J. Tumour angiogenesis. Adv Cancer Res 1985 175-203.

6 Brown R A, Weiss J B, Tomlinson I W. Angiogenic factor Tha synovial fluids resembling that from tumours. Lancet $198 \overline{0}$ 682-5.

7 Koch A E, Polverini P J, Leibovich S J. Stimulation neovascularisation by human rheumatoid synovial tissue mā rophages. Arthritis Rheum 1986; 29: 471-9.

8 Folkman J, Haudenschild C. Angiogenesis in vitro. Nature 1980; 288: 551-6.

9 Montesano R, Orci L, Vassalli J. In vitro rapid organisation endothelial cells into capillary-like networks is promoted b collagen matrices. J Cell Biol 1983; 97: 1648-52.

10 Garbett P K, Jackson C J, Brooks P M, Schrieber L. Sprofif formation and luminal development in vitro. In: Tsuchiya $M$ et al, eds. Microcirculation-an update. Vol. 2, Amsterdan? Elsevier, 1987: 805-6.

11 Garbett P K, Jackson C J, Brooks P M, Schrieber L. Vessel-like sprouts may develop from fibroblasts in vitro. Cell Biol Int $R \stackrel{P}{\text { p. }}$. 1987; 11: 835.

12 Auerbach R, Alby L, Morrissey L W, Tu M, Joseh Expression of organ-specific antigens on capillary endothelia cells. Microvasc Res 1985; 29: 401-11.

13 Stel H V, van der Kwast Th H, Veerman E C L. Detection of factor VIII/coagulant antigen in human liver disease. Natute 1983; 303: 530-2.

14 Marks R M, Czerniecki M, Penny R. Human dermal microvaso cular endothelial cells: an improved method for tissue cultufe and a description of some singular properties in culture. In Vitrog Cell Dev Biol 1985; 21: 627-35.

15 Gilbert S F, Migeon B R. D-valine as a selective agent f 6 ? normal human and rodent epithelial cells in culture. Cell 1978 5: 11-17.

16 Marks R M, Penny R. Use of diathermy for weeding heterogeneous tissue cultures. In Vitro Cell Dev Biol 1986; 22: 311-

17 Voyta J C, Via D P, Butterfield C E, Zetter B R. Identification and isolation of endothelial cells based on their increased uptake of acetylated-low density lipoprotein. J Cell Biol 1984; 99: 2034-40.

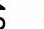

